\title{
Editor's Introduction: Science, Politics and the Fullness of Truth
}

\author{
Lawrence T. Nichols ${ }^{1}$
}

Published online: 23 May 2018

(C) Springer Science+Business Media, LLC, part of Springer Nature 2018

In this issue we present a broad range of articles, including some that are historical and some that deal with current issues and controversies. We begin with Andrew Abbot's essay on "Varieties of Normative Inquiry: Moral Alternatives to Politicization in Sociology" in which the author examines "ways of relating the normative side of sociology to its empirical side." After critiquing the weaknesses of two currently prevalent approaches, called monism and dualism, Abbott advocates the creation of a new "normative subdiscipline" that combines what are termed the canonical and legalist positions. Readers knowledgeable about the discipline's history in the United States will likely discern important continuities between Abbott's proposal and the theory and practice of Chicago sociology in both its classic and "second Chicago school" embodiments.

The following two articles provide historical analyses that challenge widely accepted views. Matthew Hughey and Devon Gross systematically examine the content of professional discourse in several academic fields regarding the relationship between W. E. B. DuBois and Max Weber. Their research identifies specific types of misconception, especially the facile assumption that DuBois was a student of Weber, and it also documents Weber's admiration of DuBois's work on race relations and racial conflict. Kaspar Villadsen next re-examines the career of Jane Addams, arguing that the ideals of early Christianity were far more central for her than has generally been recognized. The author contends that, while there may be truth in characterizing Addams as a "feminist pragmatist," such a framing is incomplete, especially insofar as it overlooks Addams's efforts to create a "Christian renaissance" based on "a new social ethics". In the process, Villadsen also takes note of Addams's high estimate of the teachings of Lev Tolstoy, especially as expressed in his book, The Kingdom of God Is Within You, a Social Gospel approach that, interestingly, also deeply influenced both Mohandas Gandhi and Pitirim Sorokin.

Lawrence T. Nichols

lnichol2@wvu.edu

1 West Virginia University, Morgantown, WV, USA 
Clayton Fordahl next provides thoughtful reflections on the idea of authenticity in sociology. Tracing the concept historically, the author notes its relocation from an association with external and transcendent forms of the good to a linkage with individual and internal perceptions. Fordahl proposes that sociologists integrate the contemporary understanding of authenticity with theoretical models of dramaturgy and social performance as a means of understanding especially "the perplexing role of authenticity in politics."

The final four articles focus on a specific debate regarding science, politics and activism. The starting point for this exchange is the article in our previous issue by Nathan Cofnas, Noah Carl and Michael Woodley, "Does Activism in Social Science Explain Conservatives' Distrust of Scientists"? This essay elicited a thoughtful critique from Julien Larregue, entitled "Conservative Apostles of Objectivity and the Myth of a 'Liberal Bias' in Science." Upon receiving this manuscript, I offered Cofnas, Carl and Woodley the standard professional courtesy of a rejoinder, which is presented here. Meanwhile, George Yancey challenged the Larregue critique in an article entitled, "Yes, Academic Bias Is A Problem," and Professor Larregue has contributed a rejoinder. We are thus able to offer readers a thoughtful mini-symposium on a set of important and enduring issues.

The debate over science and politics is traceable at least to the writings of Marx and Engels that challenged the purity and validity of the eighteenth century European ideal of rationalism by locating rationality — critically — within a social context characterized by injustice and class conflict. Significantly, Marx and Engels exempted mathematics and natural science from their reductionist critique, but they maintained that other fields of learning, as parts of the oppressive "superstructure" of class-based culture, were reflections of the relations of production rooted in domination. Thus, socially organized rationality (e.g., the field of political economy), as well as socially organized nonrationality (e.g., religions) functioned as instruments of control by elites, especially the owners of capital. In this way, a conceptual distinction emerged between "bourgeois" and "socialist" (class-conscious) ways of knowing the world, and thus knowledge became linked with membership in particular groups with opposed interests. According to this view, a unitary or universal scientific knowledge could only emerge after historical class contradictions had been resolved.

For approximately a century, the Marx-Engels approach remained marginal in academia in both Europe and the United States. At the same time, however, it became government-enforced orthodoxy in the world's first "workers' state," the Soviet Union, as well as in Soviet dominated countries in Eastern Europe, in the People's Republic of China, in North Korea, in North Vietnam and in Cuba. In all these places, "dialectical and historical materialism," in its various forms as Marxism, Marxism-Leninism, Stalinism, Maoism, etc., became the foundation of epistemology, backed by statute and military force. Within this realm, social science in general, along with other components of culture such as art and music, was understood and valued only as a tool of revolutionary transformation, as an instrument of state policy that claimed to act as the historical vanguard of oppressed people.

Meanwhile the international intellectual situation became more complex following the appearance of a type of work, especially in Germany, that came to be called "the sociology of knowledge." This of course was still rooted in the conflict view of fundamentally opposed group interests that underlay Marxism, and it was a response 
to Marxist epistemological theory. Karl Mannheim became its foremost figure, based on his influential monograph, Ideology and Utopia that raised the question of whether any generalized knowledge was possible. Interestingly, as Marx and Engels had granted an exemption to mathematicians and natural scientists, Mannheim extended one to supposedly classless intellectuals, and thus defended the possibility of knowledge consistent with earlier European understandings of "science." The most famous embodiment of this understanding was undoubtedly physicist Isaac Newton's Principia Mathematica. The laws of motion, gravitation and entropy would thus not be considered mere products of class based intellectuals and mere expressions of class interests. Everyone could accept Newton's equations as genuine knowledge.

There were other significant articulations of these issues as well. Indeed, even prior to the German sociology of knowledge movement, American pragmatist thinkers had challenged earlier ideals of objective knowledge by making observers and processes of interpretation integral to knowing. W. I Thomas, both in his individual writings and in work coauthored with his wife, Dorothy Swaine Thomas, put forward the idea of "the definition of the situation" that proved highly influential. Nearly contemporaneously, anthropologists began to advocate cultural relativism, a position championed most famously by Margaret Mead based on fieldwork in the Pacific. The "culture and personality" school in anthropology, most often associated with Clyde and Florence Kluckhohn, was likewise supportive of key postulates of social and cultural epistemology. All such developments accorded with similar events in the physical sciences, especially Einstein's general theory of relativity and Heisenberg's principle of uncertainty. Some dealt mainly with the mental operations of knowing subjects, while others focused more on group membership and some (those rooted in a conflict perspective) on partisanship — an approach that has given rise to what might be termed an "enemies mentality."

For Russian-American sociologist Pitirim Sorokin, who tried in the manner of Oswald Spengler and Arnold Toynbee to observe the entire landscape of culture over historical epochs, it was all of a piece. Modern, European and western culture (in which the "Sensate mentality" dominated), an outlook that was inherently relativistic, was approaching a crisis in which hyper-relativistic knowledge was, for practical purposes, no knowledge at all. The only way to rescue knowledge was to construct an Integral form, which was dialectical, and in which relativistic and absolute knowledge blended and corrected one another. In this formulation, absolute knowledge had deep roots in the Russian intellectual tradition of Intuitionism that posited intuition as the underpinning of all rational knowledge, including science.

Other social scientists also responded to the epistemological challenges of the 1930s. The young Robert K. Merton critiqued the excesses of German style sociology of knowledge and postulated an "ethos of science." Talcott Parsons likewise tried to defend the possibility of knowledge that was not limited by the major intellectual traditions of positivism (independent of observer) and idealism (observer dependent), and promoted the "voluntaristic theory of action" as a "frame of reference" for sociology and social science. This approach, despite its borrowing of Max Weber's term "action," had much in common with the Chicago School approach usually associated with the work of Robert Park and his students but also arguably traceable, in part, to earlier work by Jane Addams and the Hull House circle as well as gender theorist Charlotte Perkins Gilman. By this point, sociology had gained a fairly strong 
foothold in academia, especially in the United States, where it was largely compelled to imitate the natural sciences and their understanding of knowledge.

The 1930s also witnessed other conflict-based claims about science and politics in Europe, about knowledge and group membership. These happened as a result of the Hitler movement and the establishment of the Third Reich which, in keeping with its ideology of racialism, posited an invidious distinction between "Aryan" and "nonAryan" culture and science. Where Marxists saw economic interests at work, Nazi propagandists saw expressions of racial identities. And where Marxists could accept Einstein's theory as valid general knowledge, Third Reich ideologues would reject it as "non-Aryan" and an expression of alleged Jewish "cosmopolitanism." But the views on the far left and the far right concurred in rejecting the earlier Euopean ideal of rationalism and of science as the highest form of knowledge that was independent of the social characteristics of knowers. Membership was postulated as the source of knowing.

A parallel development in the 1930s, generally less well known, was the flourishing of a distinctive "Catholic sociology" in the United States. This included a national Catholic Social Science Association and an independent journal of Catholic Sociology. This perspective postulated a sharp opposition between a spiritually oriented social science rooted in the eternally valid teachings of the Church, and a secular social science based on a materialistic premise. Genuine social science knowledge, adherents asserted, had to be grounded in a correct model of the human person as a union of a temporal body and an eternal soul.

The global trauma of the Second World War placed these various debates on hold. Both natural and social scientists played important roles in the conflict, and all generally proceeded as though valid scientific knowledge was possible, and that group memberships and partisan loyalties were secondary. Intellectual controversies were largely bracketed for another time, and a pragmatist approach dominated in which there could be scientific knowledge, "for all practical purposes," which, sadly, were largely destructive and which culminated in the building of atomic weapons that inflicted mass casualties on the people of Japan.

Earlier controversies about science and politics, about non-partisan and partisan knowledge, gradually re-emerged in the postwar world, in movements such as the New Frankfurt School centered in New York. A key to understanding this re-emergence, as well as the intensity of such debates at the present moment, is the appearance of a series of civil rights movements, as well as movements of national liberation - all of which involved pressures to identify with some specific group involved in conflict. In general this meant aligning with groups seen as historical victims of oppression.

The African-American civil rights movement within the United States proved to be immensely influential in this regard, all the more so as it raised the issue of "the guilty bystander." Neutrality, in other words, increasingly came under attack as inherently unethical, even as complicity in evil. An influential expression of this position, Howard S. Becker's essay, "Whose Side Are We On?" appeared not long after the U.S. Congress passed landmark civil rights legislation, especially the Voting Rights Act of 1965. Shortly before these events, C. Wright Mills had published a manifesto-style book, Listen, Yankee! in support of the Cuban revolution. Such writings promoted the view that henceforth sociological knowledge had to be, at least in some sense, partisan and that sociologists had to take the side of "the oppressed." And this gave impetus to 
the view that sociology was a movement on the political left, though at that point what still might be called "the mainstream left," that is, the left of the Democratic party and organized labor, rather than the radical left.

The turn toward politics and away from earlier understandings of social science was likewise promoted by Alvin Gouldner's lengthy 1970 treatise The Coming Crisis of Western Sociology, which featured an attack on the previously hegemonic functionalist paradigm. Rather quickly, a neo-Marxist movement arose, featuring both classical Marxist texts and more recent New Left writings, such as Herbert Marcuse's Reason and Revolution and Michael Burawoy's Manufacturing Consent. Paolo Freire's Pedagogy of the Oppressed also appeared on the required reading list of many sociology courses. A Marxist section of the American Sociological Association was organized. Simultaneously, a self-proclaimed genre of "radical sociology" appeared, championed by authors such as Jack Roach. A new journal, The Insurgent Sociologist, was launched. Some of the new breed of conflict sociologists preferred to call themselves "critical," and the genre of "critique" spread widely in works such as Richard Quinney's Critique of the Legal Order. Immanuel Wallerstein's “world systems theory," which drew heavily on Marxist ideas, also appeared and gained a following.

In parallel fashion, a "humanist" movement appeared under the leadership of Alfred McClung Lee which, though not Marxist as such, rejected earlier, "value-free" work in sociology. At about the same time, Michel Foucault's critical writings began to acquire a following, initially in Europe and subsequently in the U.S.

Meanwhile, other civil rights or liberation movements arose, especially feminism and what was initially called gay rights. The 1970s witnessed the controversial Roe $v$. Wade decision of the U.S. Supreme Court as well as the effort to pass a gender-based Equal Rights Amendment to the U.S. Constitution. There was also a national anti-rape movement in which sociologists participated, through such studies as Linda Lyttle Holmstrom's The Rape Victim Goes to Court and the early works of Walter Dekeseredy. Meanwhile, the riot against New York City police at the Stonewall Inn gay club led to a new militancy among gay and lesbian persons and organizations. And the specialty field of victimology became prominent, led by scholars such as Stephen Schaeffer, whose family had been victims of the Nazi genocide. Schaeffer's book, The Victim and His Criminal emphasized "spiritual satisfaction" as a foundation of moral order, but it was not politically on the left as was The New Criminology, published in Britain by Ian Taylor, Paul Walton and Jock Young.

The 1980s and 1990s were characterized by a number of relativistic movements in sociology that collectively came to be known as "postmodernism." The constructionist approach to social problems, introduced in the late 1970s by Malcolm Spector and John Kitsuse, was a generally mainstream variant, rooted in pragmatism and symbolic interactionism. Its counterpart, deconstructionism, arising from the works of French philosopher Jacques Derrida, was more leftist in orientation. Meanwhile, sociolinguistics entered the discussion, with proponents drawing both on earlier works by Ferdinand de Saussere and contemporary writings by Roland Barthes, sometimes under the heading of "post-structuralism." Other philosophical works and theoretical writings in communication studies, including those of Mikhail Bakhtin on "dialogism" and Jurgen Habermas on "communicative action," also called into question the possibility of definitive knowledge in social science. 
While these events might give the impression that the political left was "where the action is" (in the phrase of Erving Goffman), the leftist view of sociology, science and politics was not entirely dominant. Indeed, the three highest ranked sociology journals in the United States-The American Sociological Review, The American Journal of Sociology, and Social Forces-moved increasingly in a "hard science" direction that favored quantitative multivariate analysis above all other methods. This trend (which Pitirim Sorokin had earlier denounced as "quantophrenia") became so strong, in fact, that earlier "classic articles" in these outlets, such as Robert Merton's "Social Structure and Anomie," or Harold Garfinkel's "Conditions of Successful Degradation Ceremonies," would have been rejected instantly, had they been submitted in the changed context. Sociologists began to polarize around quantitative versus qualitative methods, with quantitative favored by more traditionally minded and qualitative the overwhelming choice of the more political and "critical" wing.

Meanwhile, a powerful new current, the "feminization" of the field of sociology had gained momentum - a development that would strongly influence the current debate about science, politics and knowledge. Gender emerged as a specialty area; undergraduate and graduate courses in the area spread widely; a gender section of ASA was established, and the journal Gender and Society was launched. Women became increasingly represented among tenure-track faculty at universities, and many became prominent as officers of regional and national associations, as well as editors of journals. Those elected as presidents of ASA from the 1970s through the 1990s seem to have accepted a more traditional view of science and knowledge: Mirra Komarovsky (1973), Alice Rossi (1983), Matilda White Riley (1986), Joan Huber (1989), Maureen Hallinan (1996), Jill Quadagno (1998). But more recent women presidents of ASA seem to have been inclined toward or fully committed to a gender-based view of knowledge and to a "standpoint epistemology" that includes feminist ontology, feminist pedagogy and feminist method. These include Barbara Reskin (2002), Cynthia Fuchs Epstein (2006), Frances Fox Piven (2007), Patricia Hill Collins (2009), Evelyn Nakano Glenn (2010), Cecilia Ridgway (2013), Annette Lareua (2014), Paula England (2015), Ruth Milkman (2016) and Michele Lamont (2017). Prior to 1970, no women were elected as ASA presidents. Since then there have been sixteen, and since 2000, the majority of ASA presidents have been women. The same trend is evident in regional sociology associations, in the Society for the Study of Social Problems (SSSP), and in gender-based associations such as Sociologists for Women in Society. In recent years, the majority of Ph.D. degrees in sociology have been awarded to women.

These dynamics were paralleled in many respects by others focused on race and sexuality. Thus, Critical Race Theory became an influential current of thought, taught at many universities, and a W. E. B. DuBois Award was created within ASA. Meanwhile Queer Theory became prominent and an LGBT section of ASA was established.

All of these events bear on several related questions that appear in our minisymposium, Is reliable and general social science knowledge possible? Or is all knowledge inherently partisan and limited by race, gender, sexuality, social class and their "intersections"? Is sociology, as an organized field of study, a unitary knowledge project or is it an "impossible science" (as Jonathan and Stephen Turner argued) that is permanently fragmented or even "decomposing" (as Irving Horowitz asserted)? Should it be formally divided into "a scientific wing and a political wing," so as to reduce the widespread tension and conflict among proponents of these approaches - an opposition 
that has sometimes torn apart academic departments of sociology? Is it a project or movement on the political left, one whose "brand" is "social justice" and whose purpose is to combat inequality and build a non-racist, feminist, sexually inclusive, democratic socialism? Is it "for liberals and leftists only"? Is its knowledge "for members and believers only"?

Michael Burawoy, in his address as ASA president, offered an interesting compromise, a fourfold approach that is usually referred to - mistakenly - only as "public sociology." In this holistic model, professional sociology, that is, good social science (though not precisely defined) is the basis of all activity. Its form, however, is never fully settled, and it can and should be continually examined by those engaged in critical sociology. Professional sociology can also be taken beyond the academy in two main forms, namely, policy sociology and public sociology (including both traditional and "organic" forms). This "ecumenical" approach is perhaps the best anyone has devised in recent decades, and, as I have argued elsewhere, it accords with Sorokin's earlier effort to define an Integral model of sociology.

To conclude these reflections, inspired by the exchange of views in this issue over alleged partisanship in sociology, I would offer the following observations which are generally in the spirit of Max Weber's famous essay on science as a vocation.

1. When science becomes politicized, whether "to the left" or "to the right," it tends toward the reproduction of ideological doctrines, such that the answers to all important questions are, for practical purposes, "known in advance." The formulation of theoretical and empirical questions, the selection of methods, the tactics of data collection and data analysis, are often gerrymandered toward attaining ideologically correct results. The process resembles courtroom advocacy in which pre-existing commitments are buttressed by favorable evidence and "inconvenient facts" are filtered out as much as possible. Proponents sometimes engage in selfcensorship of results that are inconsistent with their political dogmas.

2. If sociology can be, as many of its practitioners seem to desire, "a movement on the left," in which no conservatives are permitted to participate, then other fields, such as economics or political science can be "movements on the right" where no liberals are permitted. And this violates, in a very fundamental way, often stated commitments by sociologists and their professional associations to diversity, inclusiveness and dialogue. At the same time, it violates the intellectual and academic freedom of students, not all of whom identify as liberal or leftist. Sociologists might do well to bear in mind - as Durkheim might have pointed out - that even in the most liberal or leftist groups there will be some who are not quite as liberal, at least on certain issues, and who will then be labeled as deviant "conservatives." Similarly, even in the most traditional groups, there will be some who are not quite as conservative, who will be labeled "liberals." A sharp dichotomy between liberals and conservatives, between left and right, a division that breeds and sustains an enemies mentality, is injurious and largely selfdestructive.

3. If all sociological knowledge is partisan, then the field will have no credibility with many external audiences who have a different understanding of science. It will not "measure up" against its intellectual peers in the natural or social sciences who still adhere to some version of what Merton called "the ethos of science." 
4. As a merely partisan, leftist project, sociology will destroy its legitimacy in academia. In the early twentieth century, critics claimed that sociology was simply another word for socialism. For several decades, professional sociologists worked very hard to overcome that accusation and to prove that the field had genuine nonpartisan knowledge to offer. But the more recent trend, for many in the field, has been to say in effect, "Yes, that is what we're about, building social justice, which can only mean building socialism." But this approach is unacceptable to many students, to parents paying tuition, to the boards of governors of academic institutions, and to many elected officials in state government, as well as to some percentage of sociologists themselves. The same would be true if sociology were merely a partisan project on the political right.

5. Some of the approaches noted above, that reduced science to ideology and group culture, have either failed in practice or been abandoned. The racialist approach of "Aryan and non-Aryan" science, rooted in bigotry and hate, has long been utterly discredited. The Catholic approach of spiritual versus secular social science has been abandoned. The Marxist view of all knowledge as class-based has been almost totally discredited and also abandoned in some of its former strongholds, especially the Soviet Union and its former satellites.

6. The strongest contemporary challenge to the idea or ideal of unitary knowledge in sociology may be feminism (including of course both male and female proponents). According to a recent statement by one feminist theorist, Einstein's famous equations about the equivalence of matter and energy are a masculine way of thinking. Leaving aside the accuracy of this claim — which I'm not competent to judge - there is the implication that science itself, as traditionally understood, is a male or masculine project that has no inherent validity. But a bifurcated field of "sociology for women only" and "sociology for men only" seems dubious and difficult to sustain. Nevertheless, given not only the increasing prevalence of women in sociology but also their increasing hegemony in academic departments and professional associations, such an opposition might remain or even intensify. Feminists might even assert - and perhaps some already have - that the whole notion of nonpartisanship is inherently masculine and therefore not binding.

7. The debate between traditional science and partisan forms of knowledge can be cast as a contest between the rational and the non-rational, between reason and passion, between the intellect and the instinctual subconscious (ala either Freud or Pareto). Or, in Max Weber's terms, it can be framed as a conflict between two types of rationality, namely, pure rationality and value rationality. In pure rationality, a proposition or a chain of reasoning can be disproven logically or empirically; whereas in value rationality this is not possible because conclusions rest upon faith, upon "the will to believe" in James's famous phrasing. The premise of traditional science is that knowers first see than then come to believe; they discover. In contrast, when partisan commitments dominate (and of course this often happened within traditional science, in disguised forms) knowers believe first and then see "with the eyes of faith." Thus, if sociologists believe that the world consists mainly of oppressive relations, then this is what they will see and assert. A case can be made that, to a significant extent, sociology in the United States has become a realm of "see no good, hear no good, speak no good"- as reflected, for instance, in the published addresses of ASA presidents 
during the past two decades. Perhaps this is an over-correction to an earlier tendency that over-emphasized the benefits of social arrangements.

8. In contemporary sociology in the U.S., it is difficult to discern a shared intellectual agenda, but one can readily recognize a political agenda, one that Christian Smith has characterized as "sociology's sacred project." A glance at the themes of the annual conferences of ASA and its regional counterparts as well as meetings of the Society for the Study of Social Problems, which are almost always some version of "inequality and injustice," quickly illumines this focus. Perhaps the creation of such a political agenda functions to prevent anomie in the field, to provide a sense of shared purpose and direction. And it may also be the result of self-selection, in the sense that many students come to sociology not to build a science, but in order to "work for change" and to "make a difference." Constructing a science does not elicit the passion of a political crusade, especially of one in which the personal identities of students are deeply involved, and when advocacy is thus largely self-advocacy.

9. If sociology is, for practical purposes, "whatever sociologists do," and if students enter the field based largely on a sense of personal grievance, then the field will very likely become more a political than an intellectual project. Putting it another way, it will become a project whose intellectual agenda (e.g., exposing the workings of oppression as "intersectionality" as in Patricia Hill Collins's formulation) is dictated by its political commitments. Such a sociology, to the extent that it becomes formulaic, will tend to be highly predictable and a target easily portrayed by critics as mere ideology and activism. In 1991, when Washington University in Saint Louis decided to eliminate its department of sociologywhich, rather shockingly, was done via a vote in the faculty senate - a professor of natural science condemned the entire field of sociology as "an empty set." That professor's own field, biology, was exempt from such attacks, anchored as it was in a more traditional view of science.

10. The ultimate goal of scientific inquiry is not only truth but the fullest possible understanding of truth. This includes not only expected but also surprising truths, not only agreeable facts but also very disagreeable and confounding facts. Almost anyone can accept portions of truth, but it is hard for almost everyone to accept the fullness of truth, especially when that conflicts with individual or group interests. Nevertheless, that is "the vocation of science," for which the name Integralism seems to me best. 